\title{
Overexpression of Rap-1A Indicates a Poor Prognosis for Oral Cavity Squamous Cell Carcinoma and Promotes Tumor Cell Invasion via Aurora-A Modulation
}

\author{
Chang-Han Chen, ${ }^{* \dagger \ddagger}$ Hui-Ching Chuang, ${ }^{\dagger \ddagger}$ Chao-Cheng Huang, ${ }^{\ddagger \S}$ Fu-Min Fang, ${ }^{\ddagger}$ Hsuan-Ying Huang, ${ }^{\ddagger \S}$ Hsin-Ting Tsai, ${ }^{\dagger \ddagger}$ \\ Li-Jen Su, ${ }^{\|}$Li-Yen Shiu, ${ }^{* *}$ Steve Leu, ${ }^{*}$ and Chih-Yen Chien ${ }^{\dagger \ddagger}$
}

\begin{abstract}
From the Center for Translational Research in Biomedical Sciences* and the Kaohsiung Chang Gung Head and Neck Oncology Group, ${ }^{\ddagger}$ Kaohsiung Chang Gung Memorial Hospital, Kaohsiung; the Departments of Otolaryngology, ${ }^{\dagger}$ Pathology, ${ }^{\S}$ and Radiation Oncology, ${ }^{\circledR}$ Kaohsiung Chang Gung Memorial Hospital and Chang Gung University College of Medicine, Kaohsiung; the Graduate Institute of Systems Biology and Bioinformatics, ${ }^{\|}$National Central University, Jhongli; and the Department of Medical Research and Development, ** Show Chwan Memorial Hospital and Chang Bing Show Chwan Memorial Hospital, Changhua, Taiwan
\end{abstract}

Accepted for publication October 12, 2012.

Address correspondence to Chih-Yen Chien, M.D., Department of Otolaryngology, Kaohsiung Chang Gung Memorial Hospital, No. 123, Ta-Pei Road, Niao Song District, Kaohsiung 833, Taiwan. E-mail: cychien3965@ adm.cgmh.org.tw.
The functions of Rap-1A in oral carcinogenesis are largely unexplored. In this study, we examined the expression of Rap-1A at different malignant stages of oral cavity squamous cell carcinoma (OCSCC). Semiquantitative RT-PCR, quantitative RT-PCR, and Western blotting were used to evaluate Rap-1A mRNA and protein expressions, respectively, in paired OCSCC patient specimens. To determine the possible correlation between Rap-1A expression and various clinical characteristics, 256 samples from patients with OCSCC were evaluated by immunohistochemical staining. Strong Rap-1A expression was a significant prognostic marker and predictor of aggressive OCSCC. The overall and disease-specific 5 -year survival rates were significantly correlated with strong expression of $\operatorname{Rap}-1 \mathrm{~A}(P<0.001)$. Functionally, overexpressed Rap-1A could promote oral cancer cell migration and invasion by Transwell chambers and wound healing assay. Conversely, the suppression of Rap-1A expression using Rap-1Amediated siRNA was sufficient to decrease cell motility. Furthermore, our data also illustrated that Aurora-A could not only induce mRNA and protein expressions of Rap-1A for enhancing cancer cell motility but also co-localize and form a complex with Rap-1A in the oral cancer cell line. Finally, immunohistochemical staining, indirect immunofluorescence, and Western blotting analysis of human aggressive OCSCC specimens revealed a significantly positive correlation between Rap-1A and Aurora-A expression. Taken together, our results suggest that the Aurora-A/Rap-1A pathway is associated with survival, tumor progression, and metastasis of OCSCC patients. (Am J Pathol 2013, 182: 516-528; http://dx.doi.org/10.1016/j.ajpath.2012.10.023)
Head and neck cancer is the sixth most common cancer worldwide and is associated with high rates of recurrence and mortality. ${ }^{1}$ In Taiwan, oral cancer caused a crude rate of death of approximately 17.7 per 100,000 persons in the general population and resulted in $>2000$ deaths in 2006 . $^{2}$ Oral cavity squamous cell carcinoma (OCSCC), a specific type of head and neck cancer, encompasses at least $90 \%$ of all oral malignant tumors. ${ }^{3,4}$ According to the epidemiologic study, the incidence of OCSCC would be 123-fold higher among patients who smoked, drank alcohol, and chewed betel nut than those who abstained. ${ }^{5}$ The treatment outcomes of OCSCC remain unsatisfied, especially in the advanced stage of tumor, and the outcomes of surgical salvage for recurrent tumors depend on the stage of recurrence. ${ }^{6-8}$

Supported by grants from Kaohsiung Chang Gung Memorial Hospital, Taiwan (CMRPG890091, CMRPG870411-870413 to C.-Y.C. and CMRPG890921, CMRPG8A0391-8A0392 to C.-H.C.), and the National Science Council (NSC-98-2314-B-182A-042-MY3, NSC-98-2314-B-182A065 to C.-Y.C. and NSC 100-2320-B-182A-001 to C.-H.C.). The Center for Translational Research in Biomedical Sciences, which performed immunofluorescence imaging, was supported by grant CLRPG871342 871343, and Chang Gung Medical Foundation at the Kaohsiung Chang Gung Memorial Hospital Tissue Bank, which provided OCSCC tissue samples, was supported by grants CLRPG870463 and CMRPG870461 (C.-C.H.). 
Tumor metastasis is the major factor in determining the aggressive phenotype of human cancers and is the major cause of cancer deaths. ${ }^{4,7,9-12}$ The process of cell metastasis is complex, including loss of contact with neighboring cells, migration through the interstitial matrix, invasion of blood and lymph vessels, and deposition in the lymph nodes. As with other cancers, OCSCC prognosis depends primarily on clinical TNM staging, tumor stage, and lymph node status; however, the 5-year survival of OCSCC patients has not improved in the past 4 decades. ${ }^{13}$ Thus, it is important to identify valuable molecular biomarkers to help early diagnosis, prognosis prediction, and novel therapeutic strategies for OCSCC patients.

Rap-1, a subgroup of the Ras family G proteins, was identified as a suppressor of Ras-dependent transformation of NIH3T3 fibroblasts. ${ }^{14}$ Two closely related Rap-1 family members exist: Rap-1A, also called Krev-1, and Rap-1B, which is encoded by separate genes but shares $95 \%$ amino acid identity. ${ }^{15}$ Rap-1A and Rap-1B proteins may possess different functions in mammalian tissues, depending on its subcellular localization. For example, Rap-1A localizes to secretory granules, salivary gland, and neutrophils, whereas Rap-1B predominantly localizes in platelets. ${ }^{16} \mathrm{Rap}-1 \mathrm{~A} / \mathrm{B}$ could be activated by a number of extracellular stimuli, including growth factors, receptor tyrosine kinase, $\mathrm{G}$ protein-coupled receptors, cytokines, and integrins. ${ }^{17-19}$ There is a growing body of evidence, direct or indirect, to illustrate that Rap-1A/B is dysregulated in a variety of cancers or cell lines, including thyroid, ${ }^{20}$ colon, ${ }^{21}$ melanoma, ${ }^{22}$ prostate, ${ }^{23}$ pancreatic, ${ }^{24}$ and squamous cell carcinoma of head and neck cancer ${ }^{25,26}$; however, some of these do not discriminate between the actions of Rap-1A or Rap-1B in human cancer tissues or cell lines. To directly assess the function of one of the Rap-1 isoforms, Rap-1A was chosen for further study. The aims of the present study were to examine the expression of Rap-1A in a large cohort of OCSCC tissues and determine its relationships with clinicopathologic variables and patient survival. Moreover, we also uncovered the biological functions of Rap-1A in oral cancer cells.

\section{Materials and Methods}

\section{Patients and Tumor Samples}

The study population included 256 patients who underwent primary surgical resection between October 1996 and August 2005 for the treatment of OCSCC without previous radiotherapy and/or chemotherapy. Clinicopathologic information for each patient, including sex, age, $\mathrm{T}$ classification, $\mathrm{N}$ classification, TNM stage, and overall survival, was obtained retrospectively from clinical records and pathologic reports. TNM status was determined according to the 2002 American Joint Committee on Cancer system. This study was approved by the Medical Ethics and Human Clinical Trial Committee at Chang Gung Memorial Hospital. The study participants included 17 women and 239 men with a mean age of 50.9 years (range, 26-87 years). Thirty-nine patients were classified as having T1, 55 as having T2, 64 as having T3, and 98 as having T4 cancer. One hundred fifty-three patients were classified as having N0, 38 as having N1, 48 as having N2b, 13 as having N2c, and 4 as having N3 cancer. Thirty-four patients were determined to be in stage I, 38 in stage II, 61 in stage III, and 123 in stage IV.

\section{RNA Extraction, Semiquantitative RT-PCR, and RT-qPCR}

Tissue samples were frozen in liquid nitrogen and stored at $-80^{\circ} \mathrm{C}$ before RNA extraction. The tissues were homogenized using a Mixer Mill Homogenizer (Qiagen, Crawley, West Sussex, UK). Total RNA was prepared from the frozen tissue samples using an RNeasy Mini Kit (Qiagen) according to the manufacturer's instructions. The RNA $(2 \mu \mathrm{g})$ was then reverse transcribed into cDNA using SuperScript II Reverse Transcriptase (Invitrogen, Carlsbad, CA). PCR was subsequently performed using $1 \mu \mathrm{L}$ of the reverse transcription products in a total volume of $25 \mu \mathrm{L}$ with 10 paired OCSCC specimens. The primers used were as follows: Rap-1A forward 5'-GGATACTGCAGGGACAGAGC- $3^{\prime}$ and reverse $5^{\prime}$-CCCTGCTCTTTGCCAACTAC- $3^{\prime}$ and glyceraldehyde-3-phosphate dehydrogenase $(G A P D H)$ forward $5^{\prime}$-GAAGGTGAAGGTCGGAGTC- $3^{\prime}$ and reverse $5^{\prime}$-GAAGATGGTGATGGGATTTC-3'. GAPDH was used as an internal control to normalize the relative amount of cDNA in each reaction. The logarithmic phase of amplification for Rap-1A was determined during our initial experiments. The reaction mixture contained $10 \mathrm{mmol} / \mathrm{L}$ Tris- $\mathrm{HCl}$, $\mathrm{pH} 8.3,1.5 \mathrm{mmol} / \mathrm{L} \mathrm{MgCl}_{2}, 50 \mathrm{mmol} / \mathrm{L} \mathrm{KCl}, 200 \mathrm{mmol} / \mathrm{L}$ dNTPs, $2 \mathrm{mmol} / \mathrm{L}$ each primer, and $1 \mathrm{U}$ of Ex Taq Polymerase (Takara, Shiga, Japan). The PCR program was as follows: $94^{\circ} \mathrm{C}$ for 1 minute, $57^{\circ} \mathrm{C}$ for 1 minute, and $72^{\circ} \mathrm{C}$ for 2 minutes for a total of 25 cycles. The RT-PCR products were separated by $2 \%$ agarose gel electrophoresis and visualized using $0.5 \mu \mathrm{g} / \mathrm{mL}$ or ethidium bromide. The product size for Rap- $1 A$ was 225 bp. For quantitative RT-PCR (RT-qPCR), Rap-1A and Aurora-A Taq-Man probe (Applied Biosystems Inc, Carlsbad, CA) were used to perform the study. Data were represented as mean $\pm \mathrm{SD}$. To analyze the distribution of tumor and adjacent noncancerous parts, we performed the Wilcoxon signed rank test between 2 groups for statistical analysis. $P<0.05$ was significant. GAPDH (Applied Biosystems) was used as an internal control for comparison and normalization of the data. Assays were performed in triplicate using Applied Biosystems model 7700 instruments.

\section{Immunoblot Analysis}

For tissue protein extraction, frozen samples were homogenized in radioimmunoprecipitation assay lysis buffer $(50 \mathrm{mmol} / \mathrm{L}$ Tris- $\mathrm{HCl}, \mathrm{pH} 7.5,150 \mathrm{mmol} / \mathrm{L} \mathrm{NaCl}, 1 \%$ NP-40, $0.5 \%$ sodium deoxycholate, and $0.1 \%$ SDS). The protein concentration in each sample was estimated by 
Bio-Rad Protein Assay (Bio-Rad, Hercules, CA). Immunoblotting was performed according to standard procedures. Antibodies used in this study include Rap-1A (polyclonal; Epitomics, Burlingame, CA), Aurora-A (monoclonal; Epitomics), and $\beta$-actin (monoclonal; Santa Cruz Biotechnology, Santa Cruz, CA). The first antibodies were detected by incubation with secondary antibodies conjugated to horseradish peroxidase (Bio/Can Scientific, Mississauga, Ontario, Canada) and developed using Western Lighting Reagent. The proteins were explored by radiography.

\section{Cell Culture, Transient Transfection, the Establishment of Stable Clones, and Luciferase Assay}

All cell culture-related reagents were purchased from Gibco-BRL (Grand Island, NY). FaDu and SCC4 cells were grown in Dulbecco's modified Eagle's medium (DMEM) containing $10 \%$ fetal bovine serum and $100 \mathrm{U} / \mathrm{mL}$ of penicillin and streptomycin (Gibco-BRL). HA-vector (pcDNA3.1), HA-Rap-1A, and HA-Aurora-A were transiently transfected into cancer cells using Lipofectamine (Invitrogen) according to the manufacturer's instructions. FaDu and SCC4 cells mixed stably and expressing Rap-1A and Aurora-A were selected with $400 \mu \mathrm{g} / \mathrm{mL}$ of G418 (Calbiochem Novabiochem, San Diego, CA) for 2 weeks. The cell were then harvested and analyzed for exogenous Rap-1A and Aurora-A expressions by Western blotting. The 5 -upstream fragments of the Rap-1A gene ( -1 to -2000$)$ were amplified from human genomic DNA and verified by sequencing. The PCR fragments were cloned into firefly luciferase reporter vector pGL3-Basic (Promega, Madison, WI) using the NheI and HindIII sites, which were designed into the forward and the reverse primers, respectively. For co-transfection experiments, $\mathrm{FaDu}$ cells were co-transfected with $100 \mathrm{ng}$ of firefly luciferase reporter plasmids (pGL3Basic or pGL3-Rap-1A), HA, HA-Aurora-A, and $10 \mathrm{ng}$ of pRL-TK Renilla luciferase internal control plasmid. After 24 hours, the luciferase activity was measured using Dual Glo Luciferase Assay System (Promega). One doublestranded synthetic RNA oligomer (5'-GCAGGGACAGAGCAAUUUUCA-3'; Ambion, Taipei, Taiwan) deduced from human Rap-1A as described previously ${ }^{22}$ and one negative control siRNA (4611G; Ambion) were used in the siRNA experiments.

\section{IHC Study, Indirect Immunofluorescence Analysis, and Microscopy}

Adjacent noncancerous and tumor OCSCC tissue samples were selected by a pathologist based on diagnosis and microscopic morphologic findings. Tissues were fixed with $10 \%$ buffered formalin embedded in paraffin and decalcified in $10 \%$ EDTA solution. Representative blocks of the formalin-fixed, paraffin-embedded tissues were cut to $4 \mathrm{~mm}$ and deparaffinized with xylene and rehydrated in a series of ethanol washes $(100 \%, 90 \%, 80 \%$, and $70 \%)$. Slides were washed with PBS and treated with $3 \% \mathrm{H}_{2} \mathrm{O}_{2}$ for 30 minutes to block endogenous peroxidase activity. Next, the sections were microwaved in $10 \mathrm{mmol} / \mathrm{L}$ citrate buffer $(\mathrm{pH} \mathrm{6.0)}$ to unmask the epitopes. After antigen retrieval, the sections were incubated with diluted anti-Rap- 1 and anti-Aurora-A antibodies for 1 hour followed by washing with PBS. Horseradish peroxidase/Fab polymer conjugate (PicTurePlus kit; Zymed, South San Francisco, CA) was then applied to the sections for 30 minutes followed by washing with PBS. Finally, the sections were incubated with diaminobenzidine for 5 minutes to develop the signals. A negative control was run simultaneously by omitting the primary antibody. The reactivity level of the immunostained tissues was evaluated independently by two pathologists who were masked to the clinical information of the patients. Between 15 and 20 high-power fields were viewed. Criteria were developed for quantitating the immunoreactivities of the Rap-1A staining in both the normal and tumor sections using a score range of 0 to +3 , where 0 indicated no positive cell staining; $+1,<5 \%$ positive cell staining; +25 , $5 \%$ to $50 \%$ positive cell staining; and $+3,>50 \%$ positive cell staining. Similarly, the stain intensity was graded as +0 , $+1,+2$, or +3 as previously described. ${ }^{16}$ The protocol for Rap-1A was followed for the quantitation for immunoreactivity of Aurora-A staining as well. The indirect immunofluorescence staining on the OCSCC biopsies was performed with anti-Rap-1A and anti-Aurora-A at room temperature for 2 hours. The sections were then washed three times with PBS with Tween 20 and incubated with goat anti-mouse-Texas Red and goat anti-rabbit-FITC (Jackson ImmunoResearch, West Grove, PA) at room temperature for 1 hour. After washing with PBST, the sections were mounted with GEL/Mount (Biomeda Corp, Foster, CA). The fluorescence images on the slips were examined using a confocal microscope (Olympus FV10i; Olympus America Inc, Center Valley, PA).

\section{Rap-1 Activity Assays}

The levels of activated Rap-1 were determined using pulldown assays with GST-fused RalGSD-RBD according to the manufacturer instructions as previously described. ${ }^{23}$ The total cell lysates were subjected to Western blotting analysis using Rap-1A antibody.

\section{ChIP Assays}

Chromatin immunoprecipitation (ChIP) assays were performed according to the protocol from Millipore (EZ-Magna ChIP G Chromatin Immunoprecipitation Kit; Millipore, Billerica, MA). FaDu cells were transfected with vehicle control and HA-fused Aurora-A according to the manufacturer's instructions as described. Chromatin was precipitated using anti-HA antibody and protein A agarose at $4{ }^{\circ} \mathrm{C}$ overnight, and immune complexes were collected by centrifugation. Normal human IgG was used as a control. Cross-links 
were then reversed at $65^{\circ} \mathrm{C}$ overnight. The purified DNA was amplified by PCR using Rap-1A promoter primers ( -3 to -227) (forward: 5'-GGATGTCTGTTTCATTAAGCTG-3' and reverse: 5'-CCAGGAACACCATTCATTCC-3'; predenaturation for 3 minutes at $94^{\circ} \mathrm{C}$, denaturation at $94^{\circ} \mathrm{C}$ for 20 seconds, annealing at $47^{\circ} \mathrm{C}$ for 30 seconds, and extension at $72^{\circ} \mathrm{C}$ for 30 seconds for a total of 30 cycles).

\section{Migration, Invasion, and Wound-Healing Assays}

Migration and invasion assays were conducted with $\mathrm{FaDu}$ vehicle, SCC4 vehicle, FaDu/Rap-1A, and SCC4/Rap-1A mixed-stable clones using 24-well Transwell chambers (8- $\mu \mathrm{m}$ pore size polycarbonate membrane; Costar, Corning, $\mathrm{NY})$. For the migration $\left(5 \times 10^{3}\right)$ and invasion $\left(1 \times 10^{4}\right)$ assays, cells were suspended in $400 \mu \mathrm{L}$ of DMEM containing 10\% FBS, then seeded into the upper chamber; $600 \mu \mathrm{L}$ of DMEM containing 10\% FBS was added to the outside of the chamber. After being cultured at $37^{\circ} \mathrm{C}$ under $5 \% \mathrm{CO}_{2} / 95 \%$ air for 24 hours, the cells on the upper surface of the membrane were removed with a cotton-tipped applicator, and the migratory cells on the lower membrane surface were fixed with methanol and stained with Giemsa (Sigma-Aldrich, Munich, Germany). Cell migration was evaluated by counting the number of $\mathrm{FaDu}$ vehicle, SCC4 vehicle, FaDu/Rap-1A, and SCC4/Rap-1A mixed-stable clone cells that had migrated by $200 \times$ phase-contrast microscopy on three independent membranes, then normalized against the vehicle cells to determine the relative ratio. For the invasion assays, $80 \mu \mathrm{g} / \mathrm{mL}$ of Matrigel (BD Biosciences, San Jose, CA) were added to the upper surface of the membrane and allowed to gel at $37^{\circ} \mathrm{C}$ overnight. Then $1 \times 10^{5}$ cells in $400 \mu \mathrm{L}$ of DMEM containing 10\% FBS was seeded into the upper chamber, whereas $600 \mu \mathrm{L}$ of DMEM containing 10\% FBS was added to the outside of the chamber. The rest of the protocol was the same as that for the migration assays. Vehicle-/HA-Rap1A-/negative control-/siRap-1A- transfectants were used in the "wound healing" assay to test the alteration of cell migration. Cells were initially seeded uniformly onto 60$\mathrm{mm}$ culture plates with an artificial "wound" carefully created at 0 hours. A P-10 pipette tip was used to scratch the subconfluent cell monolayer. Microphotographs were taken at 0 and 24 hours. Quantitative analysis of the percentage of wound healing was calculated using the distance across the wound at 0 and 24 hours, divided by the distance measured at 0 hours for each cell line.

\section{Statistical Analysis}

Several clinicopathologic factors were evaluated, including sex, age ( $<59$ versus $>60$ years), T1, T2 versus T3, T4 stage, $\mathrm{N}$ status, and TNM stage. Fisher's exact test was used to evaluate the correlation between the clinicopathologic variables and the expression of Rap-1A. $P<0.05$ was considered to be significant in all analyses. The clinicopathologic variables and the expression of Rap-1A were taken into account for the analysis of survival based on the Kaplan-Meier method; the statistical significance, defined as $P<0.05$, was assessed by the log-rank test. To determine the effect of particular prognosis factors on survival, a multivariate analysis was performed according to Cox's regression model.

\section{Results}

\section{Up-Regulation of Rap-1A Expression in OCSCC Tissues}

To study the potential role of Rap-1A in the pathogenesis of OCSCC, we first asked whether the level of Rap-1A mRNA was elevated in primary tumor tissues. Total RNA from 10 paired OCSCC tissues was extracted and analyzed for Rap$1 A$ mRNA expression by semiquantitative RT-PCR and RT-qPCR. Rap-lA was highly expressed in the tumor specimens, whereas the adjacent noncancerous tissues expressed low levels of Rap-1A (Figure 1A). Second, the patients with advanced tumor stage had significantly higher expression of Rap-1A compared with those patients with early tumor stage. Moreover, the mean expression level of Rap-1A in OCSCC was threefold $(P<0.05)$ higher than that in adjacent noncancerous oral tissue samples as analyzed by box plot (Figure 1A). We next verified the protein expression of Rap-1A in representative and paired freshly frozen tumor and adjacent noncancerous samples by Western blot, using anti-human Rap-1A antibody. The Western blot results were consistent with the observed mRNA expression of Rap-1A in OCSCC patients (Figure 1B). We next determined the Rap-1A activity in
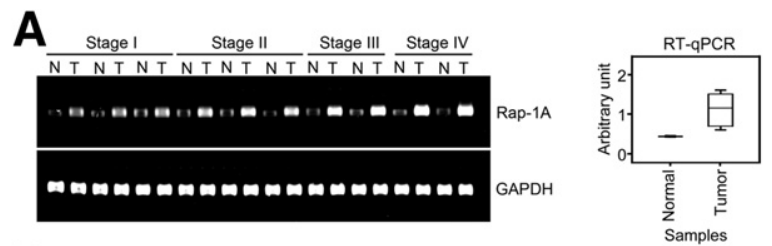

B

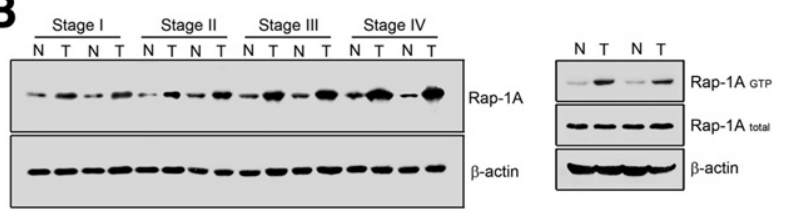

Figure 1 Rap-1A is up-regulated in OCSCC. A: RT-PCR analysis of Rap-1A expression in early and advanced stages of OCSCC samples; Rap-1A overexpression was observed in 10 paired OCSCC samples ( $\mathrm{T}$, tumor tissue; $\mathrm{N}$, adjacent noncancerous tissue) (left). Box plot of data distribution in grouping classification indicates that there is a statistically significant difference $(P<0.001)$ between tumor tissues and adjacent noncancerous tissues from the same OCSCC patients by RT-qPCR analysis (right). B: Western blot analysis of Rap-1A protein expression in 8 paired specimens (from early to advanced stages) of OCSCC patients (left). The active form of Rap-1A in 2 paired OCSCC samples was analyzed in RalGDS pull-down assay (right). The levels of activated Rap-1A were determined by Western blot analysis using an anti-Rap-1A antibody. 
OCSCC tissues. The cell lysates from two paired OCSCC tissues were prepared, and active Rap-1 GTPase was immunoprecipitated with human RalGDS-RBD-GST fusion protein from each sample with equal amounts of protein. As shown in Figure 1B, Rap-1A activity was higher in tumor tissues than that in adjacent nontumor tissues. This result suggested that higher Rap-1A expression level was coincident with increased Rap-1A activity in tumor tissues.

To investigate the clinical implications of Rap-1A in OCSCC, an immunohistochemical (IHC) analysis was performed to determine the expression and distribution of Rap-1A in 256 human OCSCC tissues, and the results were compared with the level of Rap-1A immunoreactivity in adjacent noncancerous tissues. Representative results of Rap-1A immunostaining are shown in Figure 2. First, IHC staining revealed that very weak staining of Rap-1A was observed in cytoplasm in adjacent noncancerous tissues (Figure 2B). The specificity of Rap-1A staining was confirmed by peptide neutralization, after which no significant signal could be seen (Figure 2A). Second, in the tumor samples, Rap-1A expression was positively correlated with tumor stage (Figure 2, C-F) and node stage (Figure 2, G and H) of the tumor cells. Third, Rap-1A expression was largely localized in the cytoplasm of both tumor sample cells and adjacent noncancerous tissues.

\section{Clinicpathologic Factors of OCSCC Patients with Rap-1A Expression}

To investigate whether the expression of Rap-1A was associated with various prognostic factors, including age, sex, and TNM pathologic classification, we classified the patients into two groups based on the IHC analysis: negative or low $(-/+)$ Rap-1A expression and high $(++/+++)$ Rap-1A expression. As indicated in Table 1, patients with T3/T4 tumors, TNM stage III/IV disease, and lymph node positive $(\mathrm{N}+)$ tumors had significantly higher expression of Rap-1A compared with patients with stage T1/T2 tumors $(P<0.001)$, TNM stage III/IV disease $(P<0.001)$, and lymph node negative $(\mathrm{N}-)$ tumors $(P<0.001)$. Furthermore, no significant differences were observed between high and low levels of Rap-1A with respect to the age, sex, and histologic grade at the time of diagnosis in the patients. To further confirm our results, anti-Rap-1A antibody from Abnova produced almost the same results. These findings suggest that highly expressed Rap-1A could be generally related to tumor progression of OCSCC.

\section{Survival of OCSCC Patients with Rap-1A Expression}

The mean follow-up period in this cohort was 67 months (range, 2 to 171 months). Considering that the Rap-1A expression level was associated with tumor stage, we questioned whether Rap-1A expression correlates with patient prognosis. As shown in Figure 2I, a disease-specific survival analysis using Kaplan-Meier methods revealed that
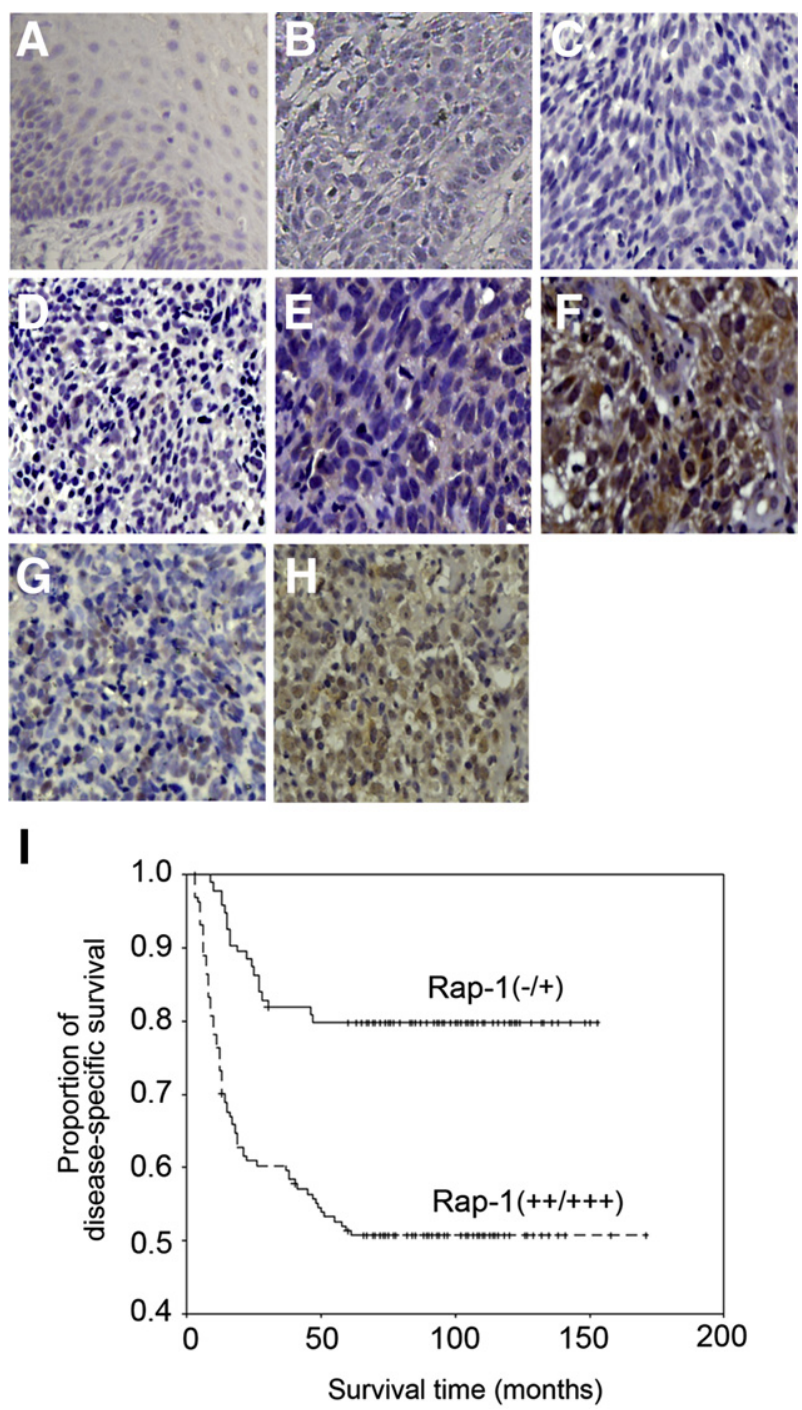

Figure 2 IHC staining and disease-specific survival of Rap-1A in patients with OCSCC. A: The staining was not observed when anti-Rap-1A antibody was preincubated with protein corresponding to a portion of Rap-1A. B: Rap-1A intensity in various tissues was evaluated by IHC staining. Adjacent nontumor tissues displayed very weak Rap-1A staining in the cytoplasm. Staining for Rap-1A was higher in tumor tissues $(\mathbf{C}-\mathbf{H})$, whereas significant cytoplasm expressions were observed in T1 (C), T2 (D), T3 (E), and T4 (F) stage tumors. Rap-1A expression levels between tumors that were lymph node negative $(\mathbf{G})$ and lymph node positive $(\mathbf{H})$. I: The 5 -year disease-specific survival period of patients with strong Rap-1A expression $(n=256)$ (dashed lines) was significantly shorter than that of patients with lower expressions (solid line). $P<0.001$, log-rank test. Original magnification, $\times 100(\mathbf{A}-\mathbf{H})$.

the prognosis of patients with higher $(++/+++)$ tumor expression of Rap-1A was significantly poorer than that of those with low $(-/+)$ expression $(P<0.001)$. Univariate analysis revealed that advanced $\mathrm{T}$ classification $(P<0.001)$, positive $\mathrm{N}$ classification $(P<0.001)$, advanced TNM stage $(P<0.001)$, and higher Rap-1A expression $(P<0.001)$ predicted a significantly worse prognosis for 5 -year diseasespecific survival and 5-year overall survival of OCSCC patients (Tables 2 and 3). Furthermore, Cox regression 
Rap-1A Modulates OCSCC Metastasis

Table 1 Clinical Profile and Correlation between the Clinicopathologic Features and Expression of Rap-1A in OCSCC

\begin{tabular}{|c|c|c|c|c|}
\hline \multirow[b]{2}{*}{ Variable } & \multirow[b]{2}{*}{ No. of patients } & \multicolumn{2}{|l|}{ Rap-1A staining } & \multirow[b]{2}{*}{$P$ value } \\
\hline & & Low expression $(-/+)$ & High expression $(++/+++)$ & \\
\hline \multicolumn{5}{|l|}{ Sex } \\
\hline Female & 22 & 20 & 2 & \\
\hline \multicolumn{5}{|l|}{ Age (years) } \\
\hline$\leq 59$ & 208 & 166 & 42 & 0.225 \\
\hline $\mathrm{T} 1, \mathrm{~T} 2$ & 54 & 52 & 2 & $<0.001^{*}$ \\
\hline T3, T4 & 202 & 42 & 160 & \\
\hline \multicolumn{5}{|l|}{$\mathrm{N}$ classification } \\
\hline Positive & 113 & 10 & 103 & $<0.001^{*}$ \\
\hline Negative & 143 & 78 & 65 & \\
\hline Well differentiated & 135 & 42 & 93 & \\
\hline Moderately and poorly differentiated & 121 & 38 & 83 & \\
\hline
\end{tabular}

*Statistically significant $(P<0.05)$.

analysis revealed that $\mathrm{T}$ classification, $\mathrm{N}$ classification, and Rap-1A expressions were the independent prognostic factors for 5-year overall survival and 5-year disease specific survival (Tables 4 and 5). These results clearly

Table 2 Correlation between the 5-Year Overall Survival Rate and Clinicopathologic Features in OCSCC

\begin{tabular}{|c|c|c|c|}
\hline Variable & $\begin{array}{l}\text { No. of } \\
\text { patients }\end{array}$ & $\begin{array}{l}5-\text { Year overall } \\
\text { survival rate }(\%)\end{array}$ & $P$ value \\
\hline \multicolumn{4}{|l|}{ Sex } \\
\hline Male & 234 & 60.8 & 0.1 \\
\hline Female & 22 & 81.9 & \\
\hline \multicolumn{4}{|l|}{ Age (years) } \\
\hline$\leq 59$ & 208 & 64.5 & 0.068 \\
\hline$\geq 60$ & 48 & 51.9 & \\
\hline \multicolumn{4}{|l|}{ T classification } \\
\hline $\mathrm{T} 1, \mathrm{~T} 2$ & 54 & 79.8 & $<0.001^{*}$ \\
\hline T3, T4 & 202 & 50.7 & \\
\hline \multicolumn{4}{|l|}{ N classification } \\
\hline Positive & 113 & 75.0 & $<0.001^{*}$ \\
\hline Negative & 143 & 41.2 & \\
\hline \multicolumn{4}{|l|}{ TNM stage } \\
\hline I, II & 72 & 89.4 & $<0.001^{*}$ \\
\hline III, IV & 184 & 52.2 & \\
\hline \multicolumn{4}{|l|}{ Histologic grade } \\
\hline Well differentiated & 135 & 63.5 & 0.285 \\
\hline $\begin{array}{l}\text { Moderately and poorly } \\
\text { differentiated }\end{array}$ & 121 & 52.8 & \\
\hline \multicolumn{4}{|l|}{ Rap-1A } \\
\hline Low expression & 95 & 79.8 & $<0.001^{*}$ \\
\hline High expression & 161 & 51.3 & \\
\hline
\end{tabular}

*Statistically significant $(P<0.05)$ indicated that the 5-year survival and clinical prognosis of OCSCC is associated with expression of Rap-1A and suggest that Rap-1A is a good prognostic factor for OCSCC patients.

Table 3 Correlation between the 5-Year Disease-Specific Survival Rate and Clinicopathologic Features in OCSCC

\begin{tabular}{|c|c|c|c|}
\hline Variable & $\begin{array}{l}\text { No. of } \\
\text { patients }\end{array}$ & $\begin{array}{l}5 \text {-Year disease } \\
\text { specific survival } \\
\text { rate }(\%)\end{array}$ & $P$ value \\
\hline \multicolumn{4}{|l|}{ Sex } \\
\hline Male & 234 & 64.8 & 0.174 \\
\hline Female & 22 & 81.9 & \\
\hline \multicolumn{4}{|l|}{ Age (years) } \\
\hline$\leq 59$ & 208 & 67.9 & 0.142 \\
\hline$\geq 60$ & 48 & 58.6 & \\
\hline \multicolumn{4}{|l|}{ T classification } \\
\hline $\mathrm{T} 1, \mathrm{~T} 2$ & 54 & 81.9 & $<0.001^{*}$ \\
\hline $\mathrm{T} 3, \mathrm{~T} 4$ & 202 & 56.6 & \\
\hline \multicolumn{4}{|l|}{$\mathrm{N}$ classification } \\
\hline Positive & 113 & 79.4 & $<0.001^{*}$ \\
\hline Negative & 143 & 45.8 & \\
\hline \multicolumn{4}{|l|}{ TNM stage } \\
\hline I, II & 72 & 90.9 & $<0.001^{*}$ \\
\hline III, IV & 184 & 57.2 & \\
\hline \multicolumn{4}{|l|}{ Histologic grade } \\
\hline Well differentiated & 135 & 65.8 & 0.305 \\
\hline $\begin{array}{l}\text { Moderately and poorly } \\
\text { differentiated }\end{array}$ & 121 & 55.6 & \\
\hline \multicolumn{4}{|l|}{ Rap-1A } \\
\hline Low expression & 95 & 82.3 & $<0.001^{*}$ \\
\hline High expression & 161 & 56.2 & \\
\hline
\end{tabular}

${ }^{*}$ Statistically significant $(P<0.05)$. 
Table 4 Risk Factors Affecting 5-Year Overall Survival Rate Determined by Cox's Regression Analysis

\begin{tabular}{llr}
\hline Variable & Relative risk $(95 \%$ CI $)$ & $P$ value \\
\hline $\begin{array}{l}\text { T classification } \\
\text { T3, T4 vs T1, T2 }\end{array}$ & $2.223(1.165-4.236)$ & $0.014^{*}$ \\
$\begin{array}{l}\text { N classification } \\
\quad \text { Positive vs negative }\end{array}$ & $2.724(1.728-4.258)$ & $<0.001^{*}$ \\
$\begin{array}{l}\text { Rap-1A expression } \\
\text { High vs low }\end{array}$ & $2.243(1.7-7.719)$ & $0.036^{*}$ \\
\hline
\end{tabular}

*Statistically significant $(P<0.05)$.

\section{Overexpressed Rap-1A Encourages the Abilities of} Migration and Invasion of Oral Cancer Cells

We next analyzed whether increased Rap-1A expression affects metastatic parameters, including migration and invasion. Two different cell types were used to evaluate this possibility. First, FaDu cells stably expressing HA-tagged Rap-1A were established. Increased Rap-1A expression was identified in two stable clones compared with the vehicle control (Figure 3A). These cells were subjected to a Transwell migration and invasion assay. The migratory ability of the FaDu-Rap-1A transfectants was approximately 4- to 5.5fold higher than that of the vehicle controls (Figure 3A). We next performed an invasion assay using a Matrigel-coated barrier filter. After 24 hours of incubation in the Matrigelcoated Transwell chamber, the FaDu-Rap-1A transfectants had invaded the basement membrane material and passed through the pores to reach the underside of the filter. Similarly, the FaDu-Rap-1A-expressing cells showed a 7- to 9.5fold higher invasive ability than the vehicle control cells (Figure 3A). Second, to address whether Rap-1A could promote cell migration in a tongue squamous cell line, SCC4 cells stably expressing HA-tagged Rap-1A at various levels were examined using Transwell chambers (Figure 3B). Quantitatively speaking, the SCC4-Rap-1A transfectants induced cell migration at a rate that was approximately 4to 5.5-fold higher than that in the vehicle SCC4 cells (Figure 3B); moreover, the invasive ability of the SCC4Rap-1A transfectants was approximately 7.5- to 8.5-fold higher than that of the vehicle controls (Figure 3B). The representative fields of cell migration and invasion experiments are shown (Figure 3C). To further characterize the role of Rap-1A in migration, we performed a wound healing

Table 5 Risk Factors Affecting 5-Year Disease-Specific Survival Rate Determined by Cox's Regression Analysis

\begin{tabular}{|c|c|c|}
\hline Variable & Relative Risk (95\% CI) & $P$ value \\
\hline $\mathrm{T}$ classification & & $0.026^{*}$ \\
\hline T3, T4 vs T1, T2 & $2.142(1.085-4.176)$ & \\
\hline $\mathrm{N}$ classification & & $<0.001^{*}$ \\
\hline Positive vs negative & $2.988(1.833-4.876)$ & \\
\hline Rap-1A expression & & $0.048 *$ \\
\hline High vs low & $3.119(1.966-9.897)$ & \\
\hline
\end{tabular}

*Statistically significant $(P<0.05)$. assay. At 24 hours after wounding, overexpressed Rap-1A cells achieved near-complete wound closure, whereas vehicle control cells did not (Figure 3D). Similar results were obtained in the SCC4 cells (data not shown). Taken together, these findings support the hypothesis that Rap-1A promotes cell migration and invasion of oral cancer cells.

\section{The Knockdown of Endogenous Rap-1A Expression by siRNAs Suppresses Oral Cancer Cell Migration and Invasion}

To further explore whether Rap-1A expression affects cell migration and invasion in human oral cancer cells, we used the siRNA approach to inhibit endogenous Rap-1A expression and assayed the migratory and invasive abilities of $\mathrm{FaDu}$ and SCC4 cells. First, a Rap-1A siRNA was transfected into $\mathrm{FaDu}$ and SCC4 cells for 24 hours, followed by Western blot analysis using antibodies against Rap-1A. The data revealed a marked reduction in the protein level of Rap-1A with siRNA (Figure 4, A and B). In addition, the negative control and Rap-1A siRNA-transfected $\mathrm{FaDu}$ and SCC4 cells were seeded into Transwell chambers with or without Matrigel. After 24 hours of incubation, the motility of the Rap-1A-siRNA-treated cells was strongly inhibited (Figure 4, A-C). Depleted Rap-1A decreased motility was also analyzed in wound-healing assays. At 24 hours after wounding, FaDu-negative control cells achieved nearcomplete wound closure, whereas depleted Rap-1A stable cells did not (Figure 4D). These results strongly suggest that Rap-1A plays an important role in human oral cancer cell migration and invasion.

\section{Rap1A Expression Is Not Only Modulated by Aurora-A But Also Participates in Aurora-A-Elicited Oral Cancer Cell Motility}

Using the concept of syn-expression, genes belonging to the same pathway often show the same regulatory profiles under a variety of biological situations. ${ }^{27}$ To map the potential signaling pathway participating in Rap-1A-elicited migration and invasion characteristics, we used a publicly accessible microarray data set of squamous cell carcinoma of the head and neck to gain insight into the functional concordance of co-expressed genes. ${ }^{28}$ To test this hypothesis, we first examined whether the mRNA expression profile of Rap-1 correlated with any modulators that were directly involved in the process of tumorigenesis in the publicly accessible microarray database. We revealed a group of genes that were overexpressed in tumor tissues compared with normal tissues, and the robust induction was observed for Aurora-A, known to be important for regulating every step in tumor development and metastasis in human cancer. This analysis raises the possibility that these two molecules are functionally linked or in the same pathway.

To determine the correlation between Rap-1A and Aurora-A in oral cancer cells, we first examined whether 
A
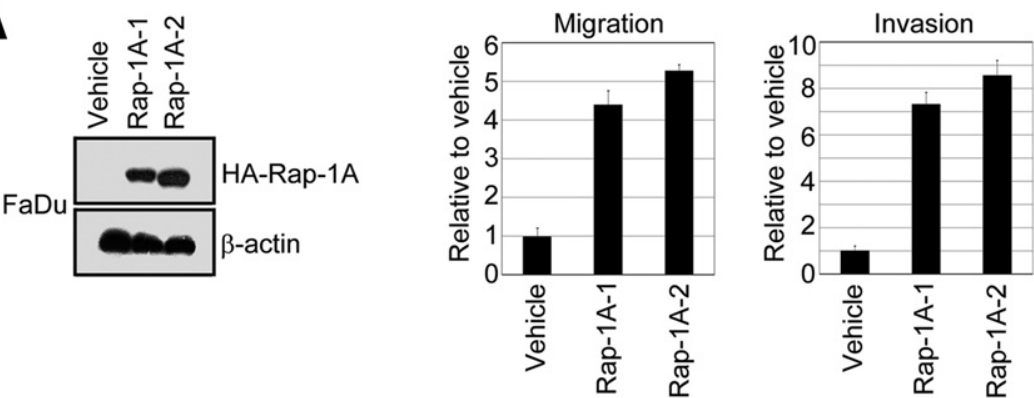

B

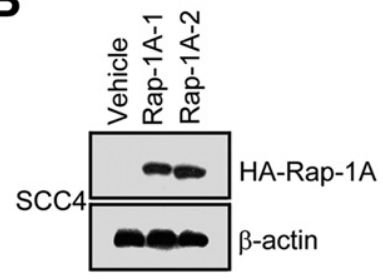

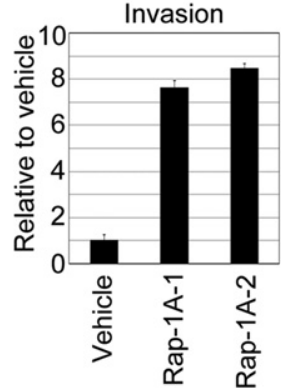

D

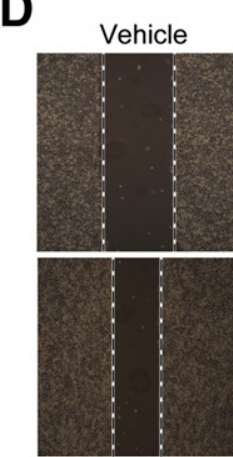

Rap-1A

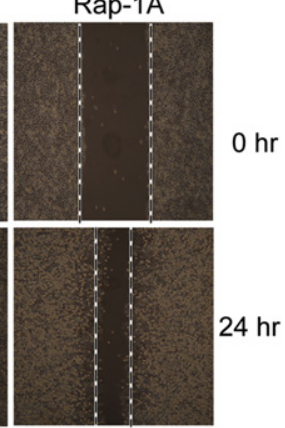

Figure $3 \quad$ A and B: Rap-1A regulates oral cancer cell migration and invasion (left panels). HA-tagged Rap-1A stable clone of FaDu and SCC4 cells were established. The cell lysates were subjected to immunoblot analysis with anti-HA antibody (middle panels). For the migration assays, cells (FaDu/SCC4 vehicle, FaDu-/SCC4-Rap-1A stable clones) were seeded into the top of a Transwell insert. After 24 hours, the cells on top were scraped, and the cells that had migrated to the bottom were fixed and stained with Giemsa. The relative-fold migration values for the clones were normalized against the vehicle control and are represented diagrammatically (right panels). For the invasion assays, cells were seeded after the addition of Matrigel. The relative-fold invasion values for the stable clones were normalized against the vehicle cells and are represented diagrammatically. C: The migration and invasion photography results of vehicle-FaDu and Rap-1AFaDu stable cells were shown. Original magnification, $\times 200$. D: Wound healing assays of the cell expressing vector or Rap-1A-FaDu cells. Representative images captured with $10 \times$ objective at the time of wounding or 24 hours after. All experiments were repeated at least three times. increased Aurora-A expression could be regulated by Rap-1A. The Aurora-A mRNA and protein levels were measured by RT-qPCR and Western blotting using FaDu-Rap-1A and FaDu-vehicle transfectants. The data indicated that overexpressed Rap-1A-FaDu transfectants could not alter the mRNA and protein expressions of endogenous Aurora-A compared with the vehicle control (Supplemental Figure S1). This finding suggests that Aurora-A may not be a downstream regulator of Rap-1A.

Next, to determine the effect of increased Rap-1A expression on Aurora-A expression, two FaDu cells stably expressing HA-tagged Aurora-A were established. As shown in Figure 5A, compared with the vehicle control, Aurora-A overexpression enhanced mRNA and protein expressions of endogenous Rap-1A. Conversely, the mRNA and protein expressions of Rap-1A were clearly reduced in the presence of the Aurora-A siRNAs in the FaDu cells (Figure 5B). To further elucidate the role of Aurora-A in regulating Rap-1 transcription, we investigated whether Aurora-A could regulate Rap-1A promoter activity. We cotransfected the Rap-1A promoter-luciferase constructs into
FaDu cells with HA-Aurora-A or vehicle control in a dosedependent manner. The data illustrated that a significant activation of the Rap-1A promoter was detected in pCMV6Aurora-A transfectants compared with vehicle control (Figure 5C). Conversely, the Rap-1A promoter activity was decreased when the Aurora-A expression was knocked down by Aurora-A siRNAs (Figure 5C). To investigate the recruitment of Aurora-A to the Rap-1A DNA region, ChIP assay was performed in FaDu cells transfected with HAAurora-A or control plasmid and immunoprecipitated with $\alpha$-HA antibody or control $\mathrm{IgG}$. The results indicated that using $\alpha$-HA antibodies were able to specifically immunoprecipitate Rap-1A promoter in cells transfected with HAAurora-A vector; however, the control IgG or vehicle transfectants did not show any amplification of Rap-1A promoter region (Figure 5D). To explore whether induced Rap-1A expression by Aurora-A overexpression could affect cell migration and invasion in human oral cancer cells, we used siRNA to inhibit endogenous Rap-1A expression and assayed the motility of $\mathrm{FaDu}$ vehicle and FaDu-Aurora-A cells. The results demonstrated that Rap-1A participated in Aurora-A-elicited motility of oral cancer 

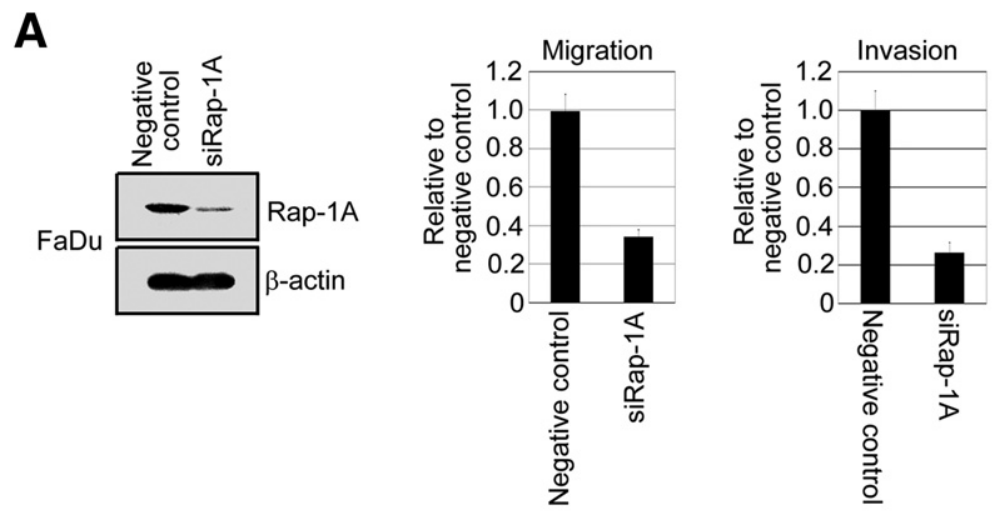

B
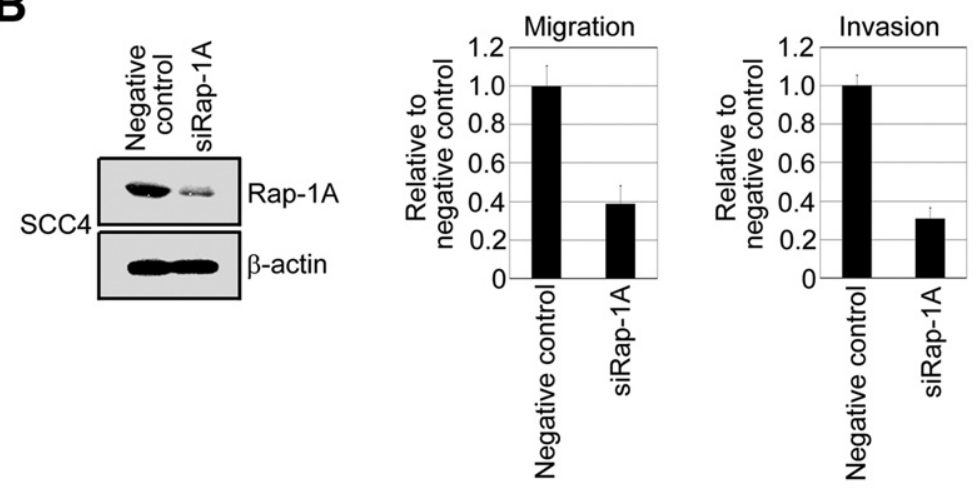

C
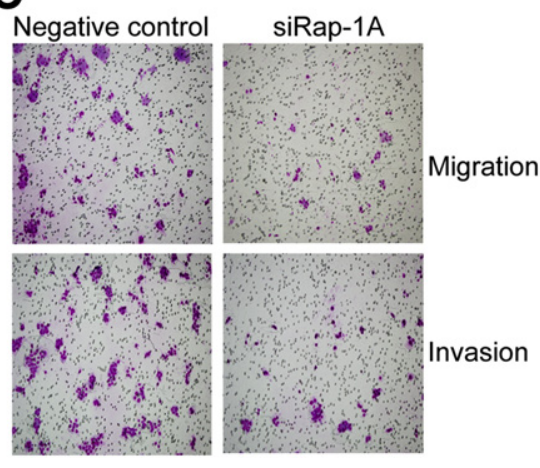

D

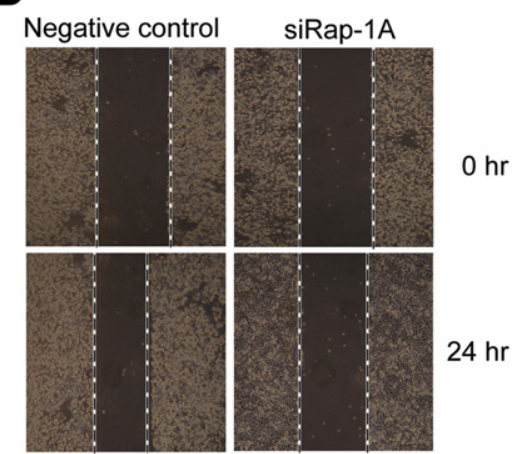

Figure $4 \quad$ A and $\mathbf{B}$ : The depletion of Rap-1A in oral cancer cell suppresses cell migration and invasion (left panels). A negative control siRNA plus Rap-1A siRNA was transfected into FaDu and SCC4 cells for 24 hours. After transfection, Western blotting was performed using anti-Rap- $1 \mathrm{~A}$ and $\beta$-actin antibodies (middle and right panels). The relativefold migration and invasion of FaDu-/SCC4-siRap-1A was normalized against the values for the negative control cells and are represented diagrammatically. All of the data represent the mean \pm SD of three independent experiments. C: The migration and invasion photography results of negative control and siRap-1A-FaDu stable cells were shown. Original magnification, $\times 200$. D: Wound healing assays of the FaDu cells transfected with negative control or siRap-1A. Representative images captured with $10 x$ objective at the time of wounding or 24 hours after. All experiments were repeated at least three times. cells (Figure 5E). These results indicated that Rap-1A is not only one of the downstream targets of Aurora-A but can also promote migration and invasion in oral cancer cells by Aurora-A modulation in human cancer cells.

\section{Rap-1A Expression Not Only Co-Localizes and Interacts with Aurora-A in Oral Cancer Cells But also Correlates with Aurora-A Expression in Aggressive OCSCC Specimens}

We next examined the protein distribution of Rap-1A in unsynchronized overexpressed Aurora-A FaDu and vehicle cells by indirect immunofluorescence. The results indicated that Rap-1A proteins not only revealed predominantly cytoplasmic localization but also co-localized with AuroraA. Furthermore, as shown in Figure 5A, the endogenous Rap-1A protein expression level was increased in Aurora-A overexpressed stable cells compared with the vehicle control (Figure 6A). Similarly, the same results were also found in SCC4 oral cancer cell lines (data not shown). We next examined whether Rap-1A binds to Aurora-A. Lysates from FaDu cells were immunoprecipitated with antibodies against Aurora-A or Rap-1A. Immunoprecipitated proteins were analyzed by immunoblotting with antibodies against Aurora-A and Rap-1. The result indicate that Aurora-A was able to bind to Rap-1A in mammalian cells. Neither of the proteins was detected in samples precipitated with human IgG (Figure 6B).

To confirm the clinical relevance of our in vitro observations concerning the regulation of Rap-1A and Aurora-A expressions, 50 samples from patients with aggressive OCSCC were examined by indirect immunofluorescence and IHC staining. Indeed, Rap-1A and Aurora-A were 
co-localized in the cytoplasm in tumor tissues of OCSCC specimens (Figure 6C). Examples of weak and strong staining for Rap-1A and Aurora-A are shown (Figure 6D). The correlation between each paired IHC scores of Rap-1A and Aurora-A was analyzed by Spearman's rank tests. The results indicate that there were positive correlations between Rap-1A and Aurora-A ( $\rho=0.786, P<0.001)$ (Table 6). In addition, the $\chi^{2}$ test was performed to assess the association between Rap-1A and Aurora-A. Rap-1 again is significantly associated with Aurora-A $(P<0.001)$ (data not shown). Finally, we performed Western blot analyses using total

A

B
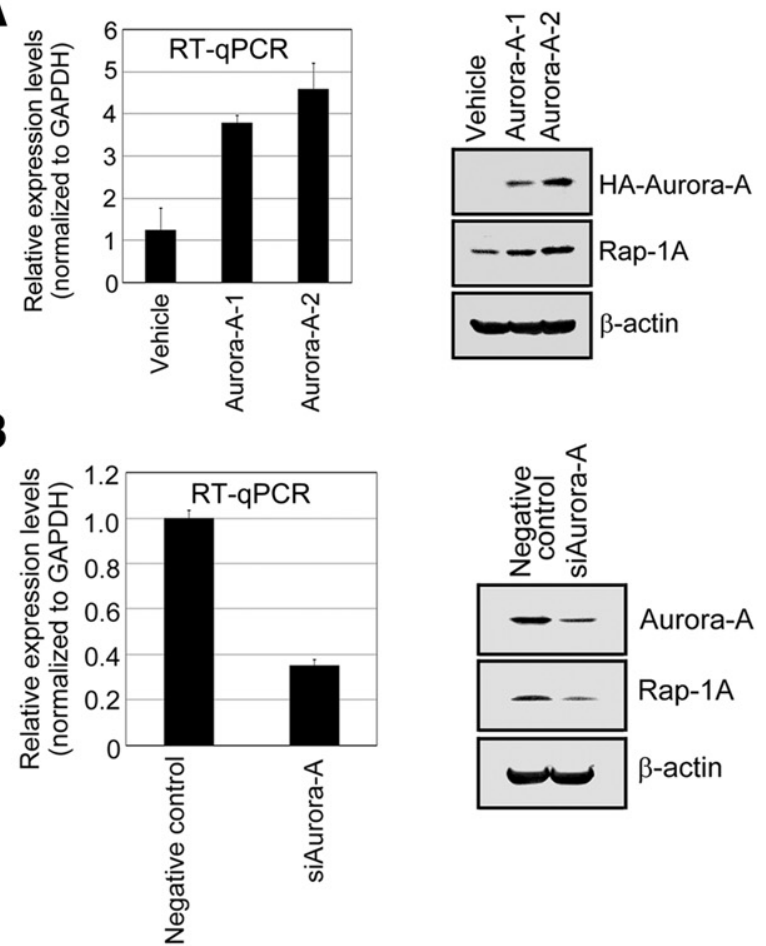

C

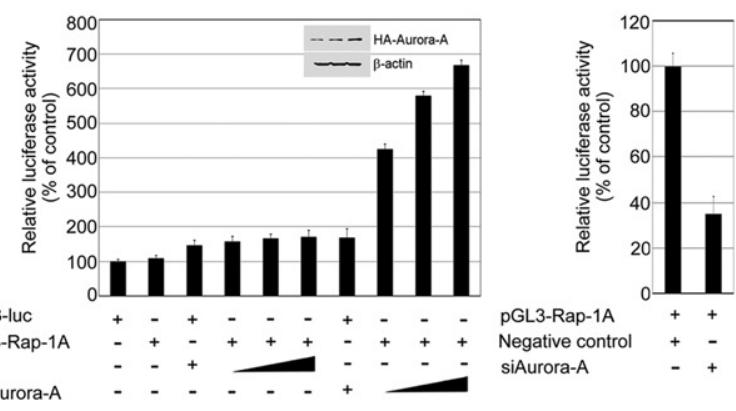

D
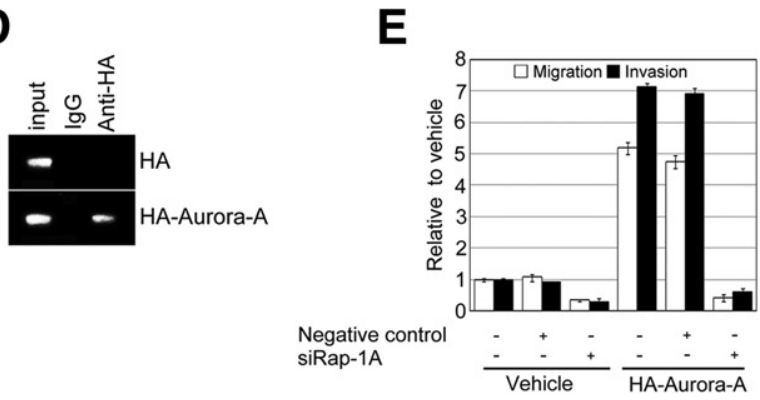

protein extracts from six tumor samples collected from patients with aggressive OCSCC. As shown in Figure 6E, the protein expression profiles of Rap-1A correlated with Aurora-A expression. Taken together, these results suggest that there is a significant positive correlation between Rap-1A and Aurora-A in human oral cancer cell lines and aggressive OCSCC specimens.

\section{Discussion}

In the current study, we describe the first systematic survey of Rap-1A expression in a large cohort of human OCSCC. Our results indicate that Rap-1A is overexpressed in primary OCSCC tissues at both mRNA and protein levels. Interestingly, overexpression of Rap-1A is associated with clinically aggressive OCSCC and correlated with $\mathrm{T}$ classification, $\mathrm{N}$ classification, and TNM stage. By Cox regression analysis, Rap-1A is an independent marker to predict poor patient outcome in OCSCC. Our results provide strong evidence that overexpression of Rap-1A could be important in determining the malignant behavior of OCSCC and may be helpful in selecting an appropriate therapeutic strategy after surgery. In addition, increased Rap-1A by Aurora-A modulation is not only co-localized and associated with Aurora-A in oral cancer cells but also required for promoting cell migration and invasion, whereas the siRNA-based repression of endogenous Rap-1A expression decreases Aurora-A-elicited cell motility. Lastly, Rap-1A-elicited cancer metastasis is correlated with elevated Aurora-A expression in specimens with aggressive OCSCC. Our findings suggest that Rap-1A is a good prognostic indicator in OCSCC and candidate molecular targets for oral cancer therapies.

Rap-1 is implicated in the regulation of growing variety of cellular responses, including integrin-mediated cell adhesion and synaptic transmission. ${ }^{29-31}$ Recent in vivo and in vitro results provide evidence that Rap- 1 is involved in

\footnotetext{
Figure 5 Aurora-A modulates Rap-1A expression that participates in Aurora-A-elicited migration and invasion in oral cancer cells. $\mathbf{A}$ and $\mathbf{B}$ : The mRNA and protein expression levels of Rap-1A were determined by RT-qPCR and Western blot analysis in overexpressing or depleted Aurora-A transfectants. The cell lysates of FaDu/Aurora-A or FaDu/siAurora-A transfectants were subjected to immunoblot analysis with anti-Rap-1A and $\beta$-actin antibodies. $\beta$-Actin was used as a control. Data are representative of three independent experiments performed in triplicate. C: The luciferase assays were performed to detect promoter activities of Rap- $1 \mathrm{~A}$ in co-transfected with in a dose-dependent manner of HA, HA-Aurora-A, or siAurora-A. The Rap-1A luciferase activity was normalized to Renilla activity. Data are representative of three independent experiments performed in triplicate. The Western blotting of HA-Aurora-A in a dose-dependent manner is shown (inset). D: ChIP analysis of endogenous Rap-1A promoter in the presence and absence of Aurora-A in FaDu cells. The protein-DNA complexes were immunoprecipitated with $\mathrm{HA}$ and $\mathrm{IgG}$ antibodies, and the Rap-1A promoter element was detected by PCR. E: The ability of cells to migrate and invade is decreased in cells transfected with Rap-1A siRNA in FaDu vehicle and FaDu-Aurora-A transfectants. The relative-fold migration and invasion values for the stable clones were normalized against the vehicle cells and are represented diagrammatically. Data are representative of three independent experiments performed in triplicate.
} 
cell proliferation, secretion, inflammation, differentiation, and migration. ${ }^{32,33}$ Dysregulation of Rap-1A/B activation has been associated with certain malignant tumors. ${ }^{25,34,35}$ There is little evidence to implicate that Rap-1A plays an important role in tumor development and invasion in human cancers, including OCSCC. To our knowledge, this is the first report to find that Rap-1A is not only overexpressed in a cohort of OCSCC specimens but also correlated with

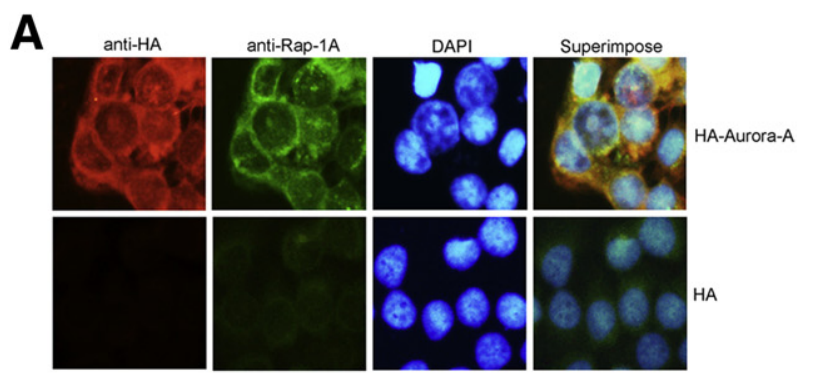

B
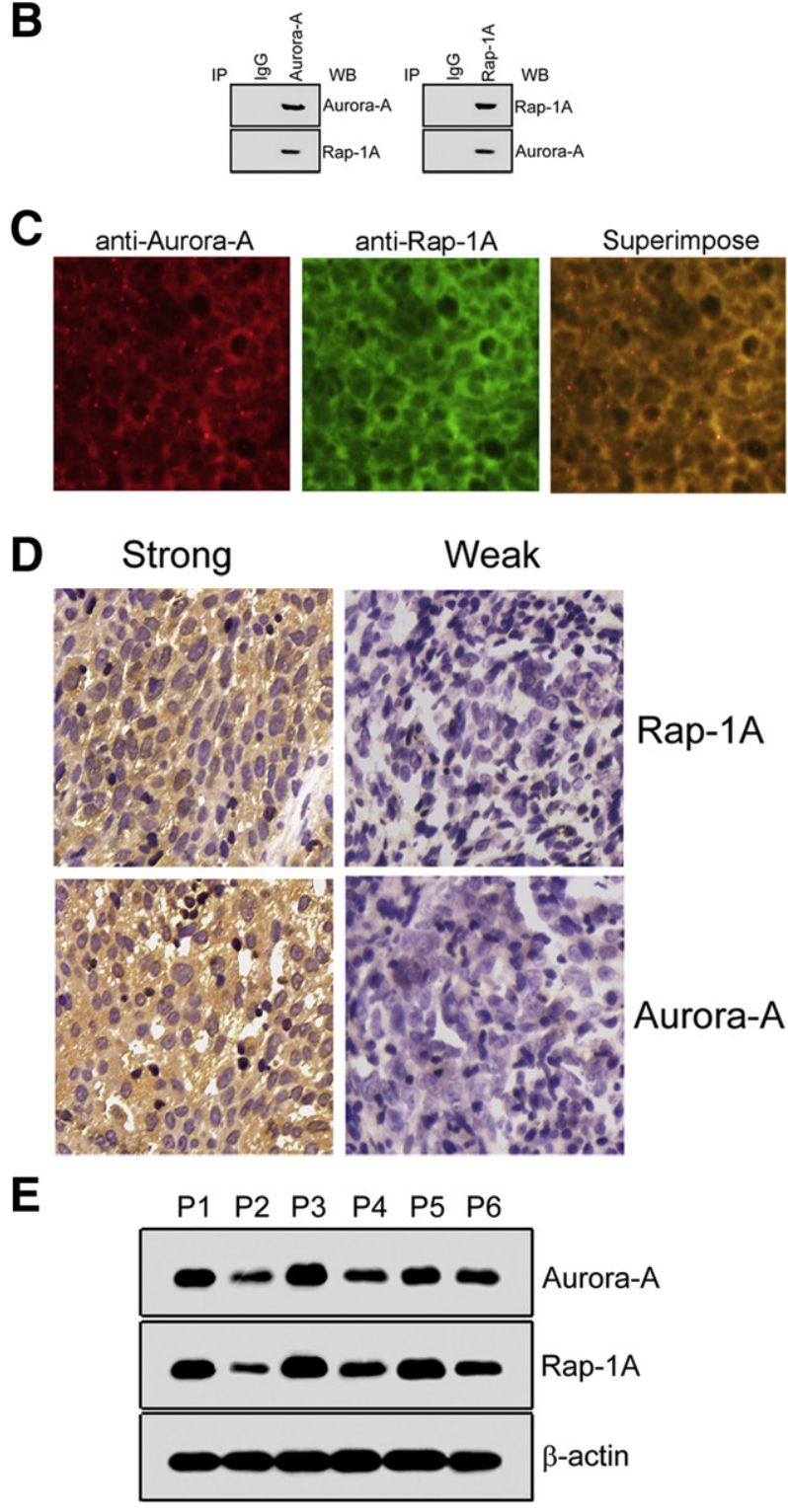

Table 6 Correlation between Rap-1A and Aurora-A Expression in Aggressive OCSCC

\begin{tabular}{lcc}
\hline & Rap-1A & Aurora-A \\
\hline Rap-1A & & \\
$\quad$ Spearman's rank correlation & 1 & \\
$\quad$ Significance (two-tailed) & 50 & \\
$\quad$ Numbers & & \\
Aurora-A & $0.786^{*}$ & 1 \\
$\quad$ Spearman's rank correlation & $<0.001$ & \\
$\quad$ Significance (two-tailed) & 50 & 50 \\
$\quad$ Numbers & & \\
\hline
\end{tabular}

*Statistically significant $(P<0.05)$.

the clinical characteristics of the advanced tumor stage. Furthermore, highly expressed Rap-1A can promote motility of oral cancer cells. These findings corroborate with other groups that aberrant Rap-1A activation contributes to several malignant tumors and leads to increased cancer cell proliferation, tumorigenesis, and metastasis. ${ }^{23,24,36,37}$

A number of proteins have been identified to regulate or interact with Rap-1 A/B to modulate Rap-1A/B activity, such as RAP1GAP, C3G, PDZ, Epac, CalDAG, and Dock4. . $^{248,39}$ Inactivation in these regulatory proteins has been identified in several cancer types. ${ }^{23}$ For instance, the mutation of Dock4 results in compromised Rap-1A/B activation in prostate and ovarian cancer. ${ }^{38}$ In addition, loss of function of Dock4 in osteosarcoma cells allows the cells to become more invasive. ${ }^{40}$ Taken together, Rap-1A/B activity modulated by these regulatory proteins allows downstream effector proteins to mediate diverse biological responses. Activated Rap-1A/B induces the mitogen-activated protein kinase-dependent signaling cascade, which has been implicated in differentiation, adhesion, and proliferation. ${ }^{25}$ Recently, it was observed that Rap-1A enhances $\beta$-catenin stability and regulates $\beta$-catenin-dependent transcription and invasion in squamous cell carcinoma of head and neck cancer. ${ }^{26}$ Accumulating evidence indicates that some growth factors mediate Rap-1A/B signaling to minimize Ras-mediated ERK activation in certain cell models. Conversely, several studies have demonstrated that Rap-1A/B could bind B-Raf to regulate ERK activation, independently of Ras in other cellular system. ${ }^{36}$ Taken

Figure 6 Aurora-A not only enhances Rap-1A expression but also colocalizes with Rap- $1 \mathrm{~A}$ in oral cancer cells and human aggressive OCSCC specimens. A: Unsynchronized HA-Aurora-A and vehicle control cells were fixed and immunostained with DAPI or antibodies against HA and Rap-1A. More than 100 cells were analyzed from multiple random frames. Representative data are shown. B: Cell lysates were immunoprecipitated with antibodies against Rap-1A, Aurora-A, or protein IgG (as a control), which was followed by immunoblotting with Rap-1A and Aurora-A. C: Rap-1A and Aurora-A expressions in human aggressiveness OCSCC specimens. Indirect immunofluorescence analysis of Rap-1A and Aurora-A in tumor cells of aggressive OCSCC specimens was performed. D: IHC staining using anti-Rap-1A or anti-Aurora-A antibodies was performed with 50 OCSCC tissue sections. Images of weak and strong staining for Rap-1A and Aurora$A$ in the sections are shown. E: The Rap- $1 \mathrm{~A}$ and Aurora-A expression levels were determined by Western blot analysis using protein extracts from six frozen tissue samples collected from patients with aggressive 0CSCC. 
together, these results indicate that the effects of Rap-1A/B on cell responses, such as proliferation, differentiation, and adhesion, are conditional, depending on the cell types.

Aurora-A is a serine/threonine kinase and a member of the Aurora/Ipllp family that is evolutionally conserved. The Aurora-A gene is located on human chromosome 20q13, and it encodes 403 amino acids that can physically associate with multiple important cellular proteins, such as p53, BRCA1, TPX2, and TACC, to regulate cell cycle progression. We used and rearranged Gaffney's gene expression microarray data set, ${ }^{28}$ and one of the candidates, Aurora-A, which was related with tumor progression, was found to positively correlate with mRNA expression level of Rap- 1 in head and neck cancer patients. It has been reported that Aurora-A overexpression is not only found in several types of human cancers but also enhances the invasion of cancer cells, including gastrointestinal cancer, bladder cancer, ovarian cancer, head and neck cancer, esophageal squamous cell carcinoma, neuroblastoma, and nasopharyngeal cancer. However, the mechanism by which Aurora-A functions in tumor development remains unclear. This is the first study, to our knowledge, to unravel an important downstream regulator of Aurora-A, Rap-1A, that may participate in oral cancer cell progression. Finally, the IHC, immunofluorescence, and Western blot analysis revealed a significant correlation that overexpression of Rap-1A elevated expression of Aurora-A in aggressive OCSCC specimens.

In summary, our findings indicate that Rap-1A may play a crucial role in tumorigenesis and progression of OCSCC. Highly expressed Rap-1A was positively correlated with tumor progression, metastasis, and 5-year disease-specific survival in OCSCC patients. Overexpression of Rap-1A in oral cancer cells contributed to the enhancement of oral cancer cell migration and invasion. Conversely, the migratory and invasive abilities of oral cancer cells were suppressed when endogenous Rap-1A was depleted by Rap-1A-mediated siRNA. Furthermore, overexpression of Aurora-A in oral cancer cells contributes to the overexpression of Rap-1A to form a complex with Rap-1A and, hence, to the induction of oral cancer cell migration and invasion. These results indicate that Rap-1A may be a critical regulator of disease progression in OCSCC, making it a potential therapeutic target. Future studies of the physiologic targets of Rap-1A and their potential roles in the pathogenesis of OCSCC will facilitate the development of novel therapeutic strategies.

\section{Supplemental Data}

Supplemental material for this manuscript can be found at http://dx.doi.org/10.1016/j.ajpath.2012.10.023.

\section{References}

1. Parkin DM, Bray F, Ferlay J, Pisani P: Global cancer statistics, 2002. CA Cancer J Clin 2005, 55:74-108
2. Chien CY, Su CY, Chuang HC, Fang FM, Huang HY, Chen $\mathrm{CH}$, Chen CM, Huang CC: Comprehensive study on the prognostic role of osteopontin expression in oral squamous cell carcinoma. Oral Oncol 2009, 45:798-802

3. Beenken SW: Head and neck tumors. Current Surgical Diagnosis and Treatment, ed 11. Edited by LW Way, GM Doherty. New York, Lange Medical Books/McGraw-Hill, 2003, pp 282-297

4. Lin YT, Chuang HC, Chen CH, Armas GL, Chen HK, Fang FM, Huang CC, Chien CY: Clinical significance of erythropoietin receptor expression in oral squamous cell carcinoma. BMC Cancer 2012, 12:194

5. Ko YC, Huang YL, Lee CH, Chen MJ, Lin LM, Tsai CC: Betel quid chewing, cigarette smoking and alcohol consumption related to oral cancer in Taiwan. J Oral Pathol Med 1995, 24:450-453

6. Chien CY, Su CY, Chuang HC, Fang FM, Huang HY, Chen CM, Chen $\mathrm{CH}$, Huang CC: Angiopoietin-1 and -2 expression in recurrent squamous cell carcinoma of the oral cavity. J Surg Oncol 2008, 97: 273-277

7. Chen $\mathrm{CH}$, Chien $\mathrm{CY}$, Huang $\mathrm{CC}$, Hwang $\mathrm{CF}$, Chuang HC, Fang FM, Huang HY, Chen CM, Liu HL, Huang CY: Expression of FLJ10540 is correlated with aggressiveness of oral cavity squamous cell carcinoma by stimulating cell migration and invasion through increased FOXM1 and MMP-2 activity. Oncogene 2009, 28:2723-2737

8. Chen CH, Su CY, Chien CY, Huang CC, Chuang HC, Fang FM, Huang HY, Chen CM, Chiou SJ: Overexpression of beta2microglobulin is associated with poor survival in patients with oral cavity squamous cell carcinoma and contributes to oral cancer cell migration and invasion. Br J Cancer 2008, 99:1453-1461

9. Steeg PS: Metastasis suppressors alter the signal transduction of cancer cells. Nat Rev Cancer 2003, 3:55-63

10. Hwang CF, Chien CY, Huang SC, Yin YF, Huang CC, Fang FM, Tsai HT, Su LJ, Chen CH: Fibulin-3 is associated with tumour progression and a poor prognosis in nasopharyngeal carcinomas and inhibits cell migration and invasion via suppressed AKT activity. J Pathol 2010, 222:367-379

11. Chen CH, Shiu LY, Su LJ, Huang CY, Huang SC, Huang CC, Yin YF, Wang WS, Tsai HT, Fang FM, Chuang WC, Kang HC, Hwang CF: FLJ10540 is associated with tumor progression in nasopharyngeal carcinomas and contributes to nasopharyngeal cell proliferation, and metastasis via osteopontin/CD44 pathway. J Transl Med 2012, 10:93

12. Chen CH, Lai JM, Chou TY, Chen CY, Su LJ, Lee YC, Cheng TS, Hong YR, Chou CK, Whang-Peng J, Wu YC, Huang CY: VEGFA upregulates FLJ10540 and modulates migration and invasion of lung cancer via PI3K/AKT pathway. PloS ONE 2009, 4:e5052

13. Sudbo J, Reith A: The evolution of predictive oncology and molecularbased therapy for oral cancer prevention. Int J Cancer 2005, 115: 339-345

14. Kitayama H, Sugimoto Y, Matsuzaki T, Ikawa Y, Noda M: A rasrelated gene with transformation suppressor activity. Cell 1989, 56: $77-84$

15. Yan J, Li F, Ingram DA, Quilliam LA: Rapla is a key regulator of fibroblast growth factor 2-induced angiogenesis and together with Rap1b controls human endothelial cell functions. Mol Cell Biol 2008, 28:5803-5810

16. Mitra RS, Zhang Z, Henson BS, Kurnit DM, Carey TE, D'Silva NJ: Rap1A and rap1B ras-family proteins are prominently expressed in the nucleus of squamous carcinomas: nuclear translocation of GTP-bound active form. Oncogene 2003, 22:6243-6256

17. Ohba Y, Kurokawa K, Matsuda M: Mechanism of the spatio-temporal regulation of Ras and Rap1. EMBO J 2003, 22:859-869

18. Quilliam LA, Rebhun JF, Castro AF: A growing family of guanine nucleotide exchange factors is responsible for activation of Rasfamily GTPases. Prog Nucleic Acid Res Mol Biol 2002, 71: 391-444

19. Itoh M, Nelson CM, Myers CA, Bissell MJ: Rap1 integrates tissue polarity, lumen formation, and tumorigenic potential in human breast epithelial cells. Cancer Res 2007, 67:4759-4766 
20. Tsygankova OM, Prendergast GV, Puttaswamy K, Wang Y, Feldman MD, Wang H, Brose MS, Meinkoth JL: Downregulation of Rap1GAP contributes to Ras transformation. Mol Cell Biol 2007, 27: $6647-6658$

21. Tsygankova OM, Ma C, Tang W, Korch C, Feldman MD, Lv Y, Brose MS, Meinkoth JL: Downregulation of Rap1GAP in human tumor cells alters cell/matrix and cell/cell adhesion. Mol Cell Biol 2010, 30:3262-3274

22. Gao L, Feng Y, Bowers R, Becker-Hapak M, Gardner J, Council L, Linette G, Zhao H, Cornelius LA: Ras-associated protein-1 regulates extracellular signal-regulated kinase activation and migration in melanoma cells: two processes important to melanoma tumorigenesis and metastasis. Cancer Res 2006, 66:7880-7888

23. Bailey CL, Kelly P, Casey PJ: Activation of Rap1 promotes prostate cancer metastasis. Cancer Res 2009, 69:4962-4968

24. Zhang L, Chenwei L, Mahmood R, van Golen K, Greenson J, Li G, D'Silva NJ, Li X, Burant CF, Logsdon CD, Simeone DM: Identification of a putative tumor suppressor gene Rap1GAP in pancreatic cancer. Cancer Res 2006, 66:898-906

25. Zhang Z, Mitra RS, Henson BS, Datta NS, McCauley LK, Kumar P, Lee JS, Carey TE, D'Silva NJ: Rap1GAP inhibits tumor growth in oropharyngeal squamous cell carcinoma. Am J Pathol 2006, 168: 585-596

26. Goto M, Mitra RS, Liu M, Lee J, Henson BS, Carey T, Bradford C, Prince M, Wang CY, Fearon ER, D'Silva NJ: Rap1 stabilizes betacatenin and enhances beta-catenin-dependent transcription and invasion in squamous cell carcinoma of the head and neck. Clin Cancer Res 2010, 16:65-76

27. Niehrs C, Pollet N: Synexpression groups in eukaryotes. Nature 1999 , 402:483-487

28. Ginos MA, Page GP, Michalowicz BS, Patel KJ, Volker SE, Pambuccian SE, Ondrey FG, Adams GL, Gaffney PM: Identification of a gene expression signature associated with recurrent disease in squamous cell carcinoma of the head and neck. Cancer Res 2004, 64:55-63

29. Kang G, Joseph JW, Chepurny OG, Monaco M, Wheeler MB, Bos JL, Schwede F, Genieser HG, Holz GG: Epac-selective cAMP analog 8pCPT-2'-O-Me-cAMP as a stimulus for $\mathrm{Ca} 2+$-induced $\mathrm{Ca} 2+$ release and exocytosis in pancreatic beta-cells. J Biol Chem 2003, 278: 8279-8285

30. Bos JL, de Bruyn K, Enserink J, Kuiperij B, Rangarajan S, Rehmann H, Riedl J, de Rooij J, van Mansfeld F, Zwartkruis F: The role of Rap1 in integrin-mediated cell adhesion. Biochem Soc Trans 2003, 31:83-86

31. Price LS, Hajdo-Milasinovic A, Zhao J, Zwartkruis FJ, Collard JG, Bos JL: Rap1 regulates E-cadherin-mediated cell-cell adhesion. J Biol Chem 2004, 279:35127-35132

32. Altschuler DL, Ribeiro-Neto F: Mitogenic and oncogenic properties of the small G protein Rap1b. Proc Natl Acad Sci U S A 1998, 95:7475-7479

33. Caron E: Cellular functions of the Rap1 GTP-binding protein: a pattern emerges. J Cell Sci 2003, 116:435-440

34. Apicelli AJ, Uhlmann EJ, Baldwin RL, Ding H, Nagy A, Guha A, Gutmann DH: Role of the Rap1 GTPase in astrocyte growth regulation. Glia 2003, 42:225-234

35. Gutmann DH, Saporito-Irwin S, DeClue JE, Wienecke R, Guha A: Alterations in the rap1 signaling pathway are common in human gliomas. Oncogene 1997, 15:1611-1616

36. Kometani $\mathrm{K}$, Ishida $\mathrm{D}$, Hattori $\mathrm{M}$, Minato N: Rap1 and SPA-1 in hematologic malignancy. Trends Mol Med 2004, 10:401-408

37. Ishida D, Kometani K, Yang H, Kakugawa K, Masuda K, Iwai K, Suzuki M, Itohara S, Nakahata T, Hiai H, Kawamoto H, Hattori M, Minato N: Myeloproliferative stem cell disorders by deregulated Rap1 activation in SPA-1-deficient mice. Cancer Cell 2003, 4:55-65

38. Frische EW, Zwartkruis FJ: Rap1, a mercenary among the Ras-like GTPases. Dev Biol 2010, 340:1-9

39. Mitra RS, Goto M, Lee JS, Maldonado D, Taylor JM, Pan Q, Carey TE, Bradford CR, Prince ME, Cordell KG, Kirkwood KL, D'Silva NJ: Rap1GAP promotes invasion via induction of matrix metalloproteinase 9 secretion, which is associated with poor survival in low N-stage squamous cell carcinoma. Cancer Res 2008, 68: 3959-3969

40. Yajnik V, Paulding C, Sordella R, McClatchey AI, Saito M, Wahrer DC, Reynolds P, Bell DW, Lake R, van den Heuvel S, Settleman J, Haber DA: DOCK4, a GTPase activator, is disrupted during tumorigenesis. Cell 2003, 112:673-684 